\title{
Interações Agressivas em Abelhas sem Ferrão: Melipona quadrifasciata (Lepeletier) Invadindo Ninho de Scaptotrigona bipunctata (Lepeletier)
}

\author{
Bruno Corrêa Barbosa ${ }^{\bowtie}$, Karine Munck Vieira \& Fábio Prezoto
}

Universidade Federal de Juiz de Fora, e-mail: barbosa.bc@outlook.com (Autor para correspondência ${ }^{\bowtie}$ ), karinemunck@yahoo.com.br, fabio.prezoto@ufjf.edu.br.

\section{EntomoBrasilis 8 (2): 152-154 (2015)}

Resumo. Este registro descreve a ocorrência de conflitos entre as abelhas sem ferrão de uma colônia ativa de Scaptotrigona bipunctata (Lepeletier) e os indivíduos de Melipona quadrifasciata (Lepeletier), e discute possíveis hipóteses que motivaram o ataque. Os comportamentos foram observados em uma colônia ativa de S. bipunctata. Os indivíduos de M. quadrifasciata que invadiram a colônia foram detidos pelos guardas do ninho ativo. As hipóteses de equívoco na identificação da entrada da colônia e erro na espécie possível à agregação foram descartadas, entretanto, a hipótese da real invasão registrada neste estudo demonstra uma estratégia comportamental de $M$. quadrifasciata e sugere que exista uma economia de energia caso tenha sucesso na pilhagem.

Palavras-Chave: Abelhas sociais; Defesa; Intrusos; Meliponini; Usurpação de ninho.

\section{Agressive Interactions in Stingless bees: Melipona quadrifasciata (Lepeletier) Invading Nest of Scaptotrigona bipunctata (Lepeletier)}

Abstract. This record describes the occurrence of conflicts between stingless bees of an active colony of Scaptotrigona bipunctata (Lepeletier) and individuals of Melipona quadrifasciata (Lepeletier), and discusses possible hypotheses that motivated the attack. Behaviors were observed in an active colony of S. bipunctata. The active nest guards detained individuals of $M$. quadrifasciata who invaded the colony. The chances of misidentification of the colony entrance and error in the species possible aggregation were discarded, however, the hypothesis of the real invasion recorded in this study demonstrates a behavioral strategy by M. quadrifasciata suggests that there is an energy savings if successful in looting.

Keywords: Defense; Intruders; Meliponini; Nest usurpation; Social bees.

( meliponíneos são abelhas sociais conhecidas como "abelhas sem ferrão" pelo fato de possuírem ferrão atrofiado, o qual não é utilizado para defesa (KeER et al. 1996). Compreendem 60 gêneros (Michenter 2007) que se distribuem pelas regiões tropicais e subtropicais do mundo, possuindo grande variedade morfológica e de hábitos de nidificação (Pirani \& Cortopassi-Laurino 1993).

A subtribo Meliponina apresenta o maior número de gêneros dentre as abelhas sem ferrão, com destaque para o gênero Scaptotrigona, reconhecida como abelhas de pequeno porte (menos de $8 \mathrm{~mm}$ ), agressivas e pouco produtivas. Scaptotrigona bipunctata (Lepeletier), formam colônias perenes com centenas a milhares de operárias (Nogueira-Neto 1970). As abelhas da espécie $S$. bipunctata constroem seus ninhos em cavidades pré-existentes, predominantemente em ocos de árvores ou subterrâneos, contendo múltiplas entradas (NogueIRA-Neto 1970; RoubiK 2006).

A espécie Melipona quadrifasciata (Lepeletier) é uma abelha com aspecto mais robusto, de tamanho de médio a grande (variando entre 7 a $15 \mathrm{~mm}$ ) (Silveira et al. 2002; Oliveira et al. 2013). Seus ninhos são construídos em cavidades e possuem a entrada ornamentada com estruturas raiadas feitas de batume, uma mistura de barro e própolis (NogueIRA-Neto 1997).

A grande quantidade de recursos (mel, pólen, cerume e resinas), armazenados nos ninhos dos meliponíneos atraem vários saqueadores, coespecíficos ou aloespecíficos (NoGUeIRA-
Neto 1997; Michener 1974). As operárias do gênero Melipona, ocasionalmente, roubam recursos ou usurpam ninhos de coespecíficos e/ou aloespecíficos e esse comportamento tornase mais frequente durante o período de escassez de alimento (Roubick 1989). Dessa forma, a fim de evitar a invasão de possíveis oportunistas, colônias de abelhas sociais são defendidas por operárias guardas na entrada do ninho, que vigiam a entrada e protegem as forrageadoras (WILSON 1971).

O objetivo do presente estudo foi, portanto, descrever a invasão de operárias de M. quadrifasciata em uma colônia de S. bipunctata, bem como o display defensivo exibido por S. bipunctata e também são discutidas as hipóteses de uma agregação de colônias ou uma real invasão que motivaram o ataque.

As observações foram realizadas no Jardim Botânico da Universidade Federal de Juiz de Fora, localizado na área urbana de Juiz de Fora, no estado de Minas Gerais (21 $43^{\circ} 28^{\prime}$ S, $43^{\circ} 16^{\prime} 47^{\prime \prime} \mathrm{W}$; elevação de 510-820m). A área consiste no domínio Mata Atlântica, que se encontra fitofisionomia de fragmento secundário de Floresta Estacional Semidecidual. O ninho de $S$. bipunctata encontra-se estabelecido em uma cavidade no tronco de uma árvore de Cupressus sp. Foram realizadas quatro visitas na colônia entre Setembro e Outubro de 2013, período compreendido na estação chuvosa, sempre no período de 9 h às $12 \mathrm{~h}$ e os comportamentos foram registrados utilizando o método ad libitum sensu Altmann (1974).

Agência(s) de Financiamento: CAPES e CNPq. 
Toi possível observar indivíduos de $M$. quadrifasciata sobrevoando a abertura da colônia das $S$. bipunctata, invadindo a entrada pelo tubo de cerume endurecido (Figura 1A), também pôde ser observado algumas operárias na árvore caminhando até a entrada da colônia (Figura 1B). As operárias guardas de $S$. bipunctata se aglomeravam na ponta do tubo de cerume, em um número muito superior as invasoras, evitando a entrada das invasoras, permitindo apenas que operárias campeiras passassem. As abelhas podem discriminar companheiras de não companheiras usando sinais químicos, os quais apresentam odores específicos de cada colônia (STUART 1988; VAN ZwEDEN \& D'ETTORRE 2010), atividade essa nem sempre eficiente, podendo apresentar falhas que possibilitam a entrada de invasores na colônia. Durante as observações, foram registradas várias entradas de operárias de $M$. quadrifasciata na colônia, sendo atacadas por várias operárias de $S$. bipunctata. Em nenhum momento foi observada a saída das invasoras do ninho de $S$. bipunctata.

Rouвıк (2006) relata que o gênero Melipona pode apresentar comportamento de agregação a outras colônias de mesma espécie ou espécies diferentes em caso de destruição de suas colônias, contudo não há relato desse comportamento para o gênero Scaptotrigona. Assim, a hipótese levantada de que tenha ocorrido um equívoco pelas $M$. quadrifasciata quanto à espécie suscetível a agregação foi descartada, tendo em vista que, além das abelhas apresentarem alta sensibilidade a sinais químicos de suas companheiras, a colônia das $M$. quadrifasciata estava intacta não justificando a intenção de agregação.

Uma segunda hipótese é de uma real invasão da colônia vizinha para usurpação de recursos e corrobora as descrições de invasões de Meliponideos a outras colônias de Meliponinae encontradas na literatura (Cortopassi-Laurino 2004; RoubiK 2006; CAStro et al. 2009). Descarta-se, assim a hipótese de que ocorreu equívoco na entrada, pois acredita-se que as abelhas utilizam memória de curto, médio e longo prazo, no caminho de volta para o ninho, além de dicas ambientais e visuais de diversos tipos, tais como campo magnético da terra e posição do Sol (GIL et al. 2007).

A tentativa de invasão observada corrobora uma estratégia comportamental já descrita de $M$. quadrifasciata que sugere a existência de uma economia de energia caso tenha sucesso na pilhagem. Contudo, pode-se destacar o fato de que não houve recrutamento de uma massiva quantidade de operárias de M. quadrifasciata para auxiliar a invasão, devido ao fato dos soldados de S. bipunctata não permitirem que as invasoras saíssem da colônia invadida, assegurando sua integridade e fracassando a tentativa de invasão.
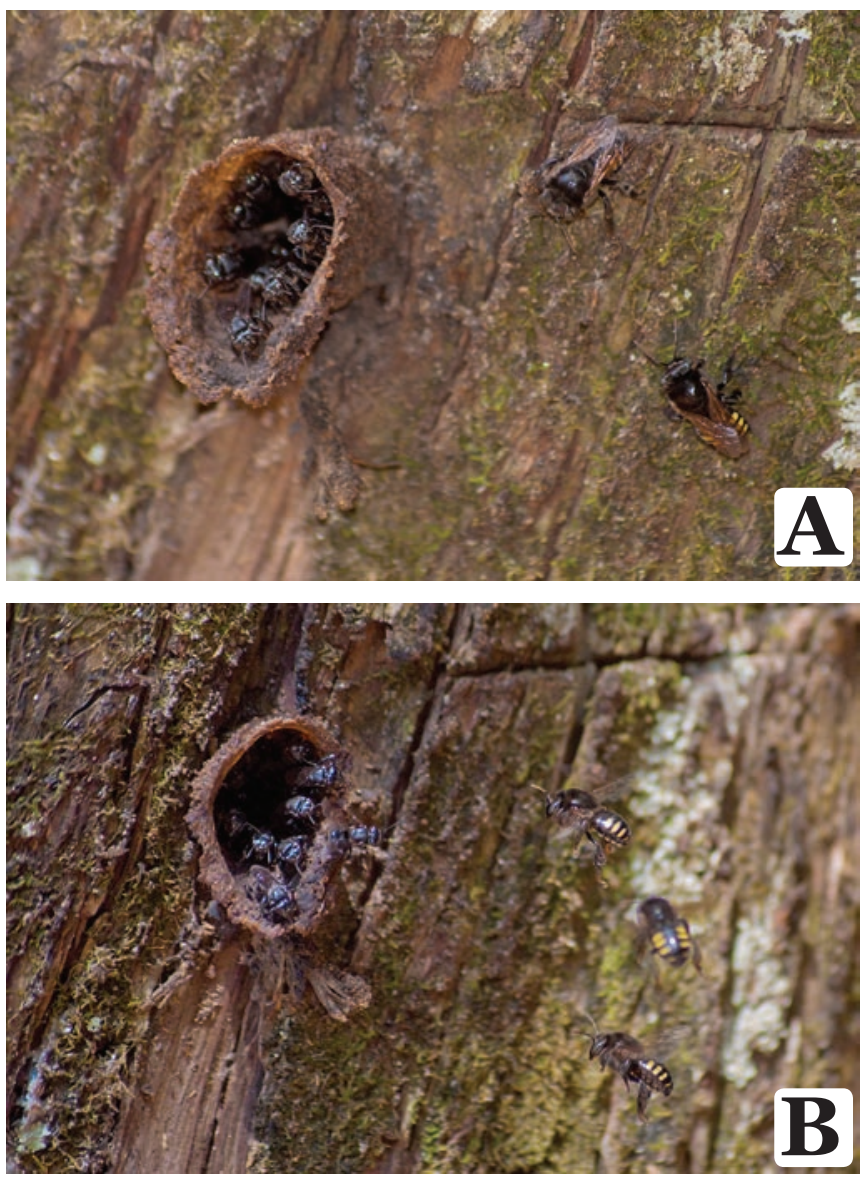

Figura 1: Colônia de S. bipunctata sendo invadida por M. quadrifasciata: (A) operárias de M. quadrifasciata pousados $e$ (B) operários sobrevoando; (C) Colônia de próxima de M. quadrifasciata. Autor: B.C. Barbosa

\section{REFERÊNCIAS}

Altmann, J., 1974. Observation study of behavior: sampling methods. Behaviour, 49: 223-265.

Castro, L.C., P.N. Silva \& F. Prezoto, 2009. Unusual nesting behavior in a neotropical stingless bee, Nannotrigona testaceicornis (Hymenoptera: Apidae). Sociobiology, 53: 569-572,

Cortopassi-Laurino, M., 2004. A Uruçu Boi da Amazônia, Melipona fuliginosa Lepeletier, 1836. Mensagem Doce, 77: $1-3$.

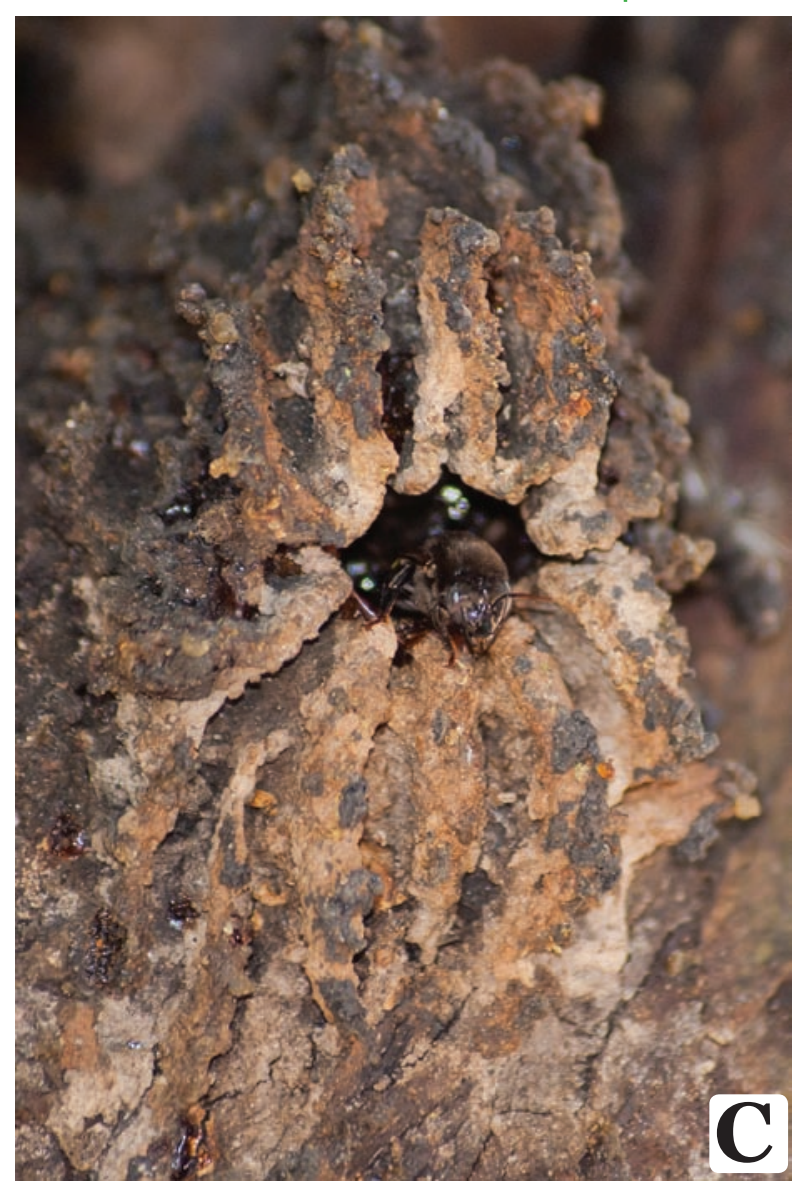

Gil, M., R.J. De Marco \& R. Menzel, 2007. Learning reward expectations in Honeybees. Learning \& Memory, 14: 491496.

Kerr, W.E., G.A. Carvalho \& V.A. Nascimento, 1996. Abelha uruçu - biologia, manejo e conservação. Fundação Acangaú, Belo Horizonte, 144p.

Michener, C.D., 1974. The Social Behavior of the Bees: a comparative study. Massachusetts, Harvard University Press, $404 \mathrm{p}$.

Michener, C.D., 2007. The bees of the World. Baltimore, D.C, John Hopkins, 953 p. 
Nogueira-Neto, P., 1970. A Criação de Abelhas Indígenas sem Ferrão. Chácara e Quintais, São Paulo, Brasil, 365 p.

Nogueira-Neto, P., 1997. Vida e criação de abelhas indígenas sem ferrão. Nogueriapis, São Paulo, Brasil, 445 p.

Oliveira, F.F., B.T.T. Richers, J.R. Silva, R.C. Farias \& T.A.L. Matos, 2013. Guia Ilustrado das Abelhas "Sem-Ferrão" das Reservas Amanã e Mamirauá, Amazonas, Brasil (Hymenoptera, Apidae, Meliponini). Tefé, Instituto de Desenvolvimento Sustentável Mamirauá, $267 \mathrm{p}$.

Pirani, J.R. \& M. Cortopassi-Laurino, 1993. Flores e Abelhas em São Paulo. EDUSP/FAPESP, 192 p.

Roubik, D.W., 1989. Ecology and Natural History of Tropical Bees. Cambridge University Press, New York, 514 p.

Roubik, D.W., 2006. Stingless bee nesting biology. Apidologie, 37: 124-143.

Silveira, F.A., G.A.R. Melo \& E.A.B. Almeida, 2002. Abelhas brasileiras: sistemática e identificação. Belo Horizonte, 253 p.
Stuart, R.J., 1988. Collective cues as a basis for nestmate recognition in polygynous leptothoracine ants. Proceedings of the National Academy of Sciences, 85: 4572-4575.

Van Zweden, J.S. \& P. D'Ettorre, 2010. Nestmate recognition in social insects and the role of hydrocarbons. Insect Hydrocarbons, 11: 222-243.

Wilson, E.O., 1971. The Insect Societies. Cambridge, Massachusetts: Belknap Press, 548 p.

\section{Recebido em: 06/10/2014}

Aceito em: 11/o3/2015

Como citar este artigo:

Barbosa, B.C., K.M. Vieira \& F. Prezoto, 2015. Interações Agressivas em Abelhas sem Ferrão: Melipona quadrifasciata (Lepeletier) Invadindo Ninho de Scaptotrigona bipunctata (Lepeletier). EntomoBrasilis, 8 (2): 152-154.

Acessível em: $\underline{\text { doi:10.12741/ebrasilis.v8i2.472 }}$
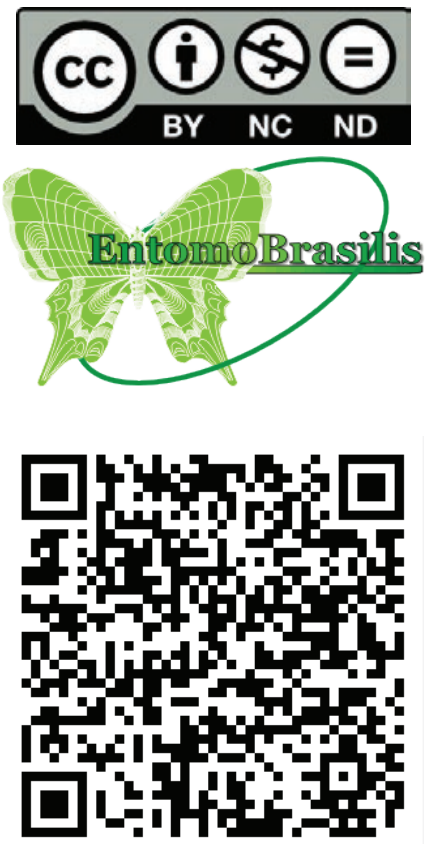